\title{
The role of IncRNA MALAT1 in bone metastasis in patients with non-small cell lung cancer
}

\author{
MEIJUAN LIU, WANLI SUN, YONGQUAN LIU and XIUHONG DONG \\ Department of Clinical Medicine, The Affiliated Hospital of Weifang Medical College, \\ Weifang, Shandong 261031, P.R. China
}

Received May 27, 2016; Accepted July 2, 2016

DOI: $10.3892 /$ or.2016.4909

\begin{abstract}
IncRNA metastasis-associated lung adencarcinoma transcript 1 (MALAT1) plays an important role in the metastasis of lung cancer. Yet, its role in bone metastasis and the related mechanism remain unknown. The present study aimed to investigate the role of lncRNA MALAT1 in the bone metastasis of non-small cell lung cancer (NSCLC), including the expression pattern in tumor tissues, and the effect on the apoptosis, proliferation, migration and invasion of NSCLC cells. The expression level of MALAT1 in NSCLC tissues with/without bone metastasis and in NSCLC cell lines with (ACC-LC-319/bone2)/without (SPC-A1) bone metastatic ability was determined with qRT-PCR and compared with t-test. si-MALAT1 was used to downregulate the expression of MALAT1 in ACC-LC-319/bone2 cells. The proliferation ability was assessed by MTT assay, and the apoptosis, migration, invasion and tumorigenesis in vivo were also assessed to detect the effect of MALAT1 expression on NSCLC cells. In conclusion, the present study found that MALAT1 was significantly highly expressed in NSCLC tissues with bone metastasis and in NSCLC cell lines with high bone metastatic ability $(\mathrm{P}<0.0001)$. Downregulation of MALAT1 expression significantly inhibited proliferation and induced cell apoptosis in comparing with the negative controls. Our results also revealed that MALAT1 significantly increased the migration, invasion and tumorigenesis in vivo, which suggests its important role in the bone metastasis of NSCLC.
\end{abstract}

\section{Introduction}

Lung cancer accounts for the majority of cancer-related death worldwide, with more than 226,000 new cases in the US in 2012. The predominant type of lung cancer is non-small cell lung cancer (NSCLC) which includes adenocarcinoma and

Correspondence to: Professor Xiuhong Dong, Department of Clinical Medicine, The Affiliated Hospital of Weifang Medical College, 2428 Yu'he Road, Weifang, Shandong 261031, P.R. China E-mail: dongxh_wf@163.com

Key words: lncRNA MALAT1, non-small cell lung cancer, bone metastasis, proliferation, apoptosis, migration, invasion squamous cell carcinoma, which makes up $\sim 85 \%$ of all new diagnoses (1-3). Despite recent advances in surgical treatment, radiotherapy and chemotherapy, the prognosis of lung cancer is still unfavorable, with a 5-year overall survival rate of 11-15\% after diagnosis $(4,5)$. Thus, a greater understanding of the molecular mechanisms underlying NSCLC development and progression is essential for improving diagnosis, prevention and treatment of this disease.

Recently, studies using high-throughput transcriptome analysis have revealed that over $90 \%$ of the total mammalian genome can be transcribed, whereas only $2 \%$ of the transcribed genome codes for protein (5), with the remaining short or long non-coding RNAs (IncRNAs) with limited or no protein-coding capacity $(6,7)$. IncRNAs are non-coding RNAs that are longer than 200 nucleotides in length, with a large range of functions in diverse biological processes including regulation of cellular development and differentiation, modulation of proliferation, apoptosis and invasiveness of tumors, and reprogramming of induced pluripotent stem cells (8-12). However, few studies have characterized the mechanisms involved in the functions of lncRNAs, which involve the regulation of gene expression by chromatin remodeling, regulation of mRNA splicing, histone protein modification and acting as sponges for microRNAs (9-12).

Accumulating evidence suggests that dysregulation of lncRNAs occur in various types of cancers, such as hepatocellular carcinoma (HCC), breast, bladder, melanoma and prostate cancer (13-18). Recent studies have also found that lncRNAs play important roles in cancer development, metastasis and chemotherapy resistance. Moreover, previous studies have also demonstrated that lncRNAs act as proto-oncogenes or tumor-suppressor genes $(19,20)$. For example, lncRNA HOX antisense intergenic RNA (HOTAIR) has been reported as a negative prognostic indicator in breast, liver and pancreatic cancer, and is associated with breast cancer metastasis $(21,22)$. Another study found that lncRNA GAS5 was downregulated in HCC tissues and may be an independent prognostic factor and potential valuable biomarker for HCC patients (23). Similar results were found for IncRNA HOTAIR, which was significantly upregulated and acted as an independent prognostic factor of recurrence in stage Ta/T1 urothelial carcinoma (24). There is also growing evidence indicating that lncRNAs may be involved in the pathogenesis of NSCLC, providing new insights into the biology of this disease $(25,26)$. 
Metastasis-associated lung adencarcinoma transcript 1 (MALAT1), mapped to human chromosome 11q13, is an evolutionarily highly conserved lncRNA which cannot be translated into protein in vivo. MALAT1 was originally demonstrated as a prognostic marker for metastasis and patient survival in NSCLC, although it is a well-described lncRNA widely expressed in normal tissues (27-29). However, it is particularly overexpressed in various carcinomas including lung, cervical, liver and bladder $(26,30,31)$, and also confers proliferative and metastatic phenotypes to tumor cells $(26,32)$. In addition, MALAT1 may be a candidate biomarker for NSCLC, particularly in early-stage metastasizing NSCLC (33). The mechanisms of MALAT1-induced tumor growth and metastasis are still unknown, including binding to the active regions of chromosomes (14), recruiting SR family proteins (13) and regulating alternative splicing of oncogenic mRNAs (15), depending on tissue contexts. There is also much evidence suggesting that MALAT1 may be involved in cell cycle regulation, which contributes to uncontrolled tumor growth.

The role of MALAT1 in lung cancer has been widely researched, yet its role in bone metastasis has not yet been investigated. The present study aimed to investigate the role of lncRNA MALAT1 in the bone metastasis of NSCLC, including the expression pattern in tumor tissues and its effect on the apoptosis, proliferation, migration and invasion of NSCLC cells.

\section{Materials and methods}

The procedures followed have been approved by the Ethics Committee of the Affiliated Hospital of Weifang Medical College, Weifang, China. Informed written consents were provided by all patients who participated in the present study. Tissue samples of NSCLC were obtained from 40 patients who underwent primary surgical resection or needle biopsy of NSCLC between 2012 and 2014 collected at the Affiliated Hospital of Weifang Medical College. Among the patients, 20 patients were diagnosed with NSCLC of stage I and the remaining 20 patients were diagnosed with NSCLC with bone metastasis. None of the patients had received radiotherapy or chemotherapy prior to surgery. NSCLC tissues were immediately snap-frozen in liquid nitrogen and stored at $-80^{\circ} \mathrm{C}$ until total RNA was extracted.

Cell lines. A normal human lung adenocarcinoma cell line (SPC-A1), a normal human bronchial epithelial cell line (16HBE), and a human lung adenocarcinoma cell line (ACC-LC-319/bone2) with high bone metastatic ability were purchased from Shanghai Institutes for Biological Sciences, Chinese Academy of Sciences (Shanghai, China). The cells were cultured in Dulbecco's modified Eagle's medium (DMEM), supplemented with $10 \%$ fetal bovine serum (FBS), antibiotic-antimycotic mixture and incubated at $37^{\circ} \mathrm{C}$ in $5 \%$ $\mathrm{CO}_{2}$.

RNA isolation and quantitative real-time PCR. Tissues were homogenized and total RNA was isolated using the TR RNA isolation kit (Invitrogen, Carlsbad, CA, USA). Then, RNA was reversely transcribed into cDNAs with a reverse transcription kit (Promega, Madison, WI, USA) according to the manufacturer's protocol. The expression of lncRNA MALAT1 was determined by quantitative real-time PCR using the following primer sequences: MALAT1 forward, 5'-GAATTGCGTCATTTAAAGCCTAGTT-3' and reverse, 5'-GTTTCATCCTACCACTCCCAATTAAT-3'. GAPDH was also included as an internal control, and the relative expression level of MALAT1 was normalized to GAPDH. qRT-PCR was performed using the FastStart Universal SYBR-Green Master Mix kit (Roche, San Francisco, CA, USA) according to the manufacturer's instructions. Each experiment was carried out in triplicate. Differences in gene expression, expressed as foldchanges, were calculated using the $2^{-\Delta \Delta C t}$ method.

Small interfering RNA and cell transfection. The small interfering RNAs (siRNAs) against MALAT1 (si-MALAT1) and the negative control (si-NC) were employed and synthesized by GenePharma (Shanghai, China). The siRNA sequences were: 5'-GAGGUGUAAAGGGAUUUAUTT-3'. Exponentially growing cells $\left(1.5 \times 10^{5}\right)$ were seeded into 12 -well plates overnight, and then transfected with siRNA or the negative control at a final concentration of $30 \mathrm{nM}$ using X-tremeGENE transfection reagent (Ambion, Austin, TX, USA). The transfection efficiency was determined by qRT-PCR $48 \mathrm{~h}$ after transfection.

Cell proliferation assay. The proliferation of the ACC-LC319/bone2 cells was assessed by MTT assay (Sigma) using the Cell Counting Kit-8 (CCK-8) (Dojindo, Japan) according to the manufacturer's instructions $24 \mathrm{~h}$ after transfection. The cells were trypsinized, counted and seeded into 96 -well plates with the cell density adjusted to $4 \times 10^{3} /$ well. At 12,24 and $48 \mathrm{~h}$, $100 \mu \mathrm{g}$ of MTT reagent was added to each well and incubation was carried out for $1 \mathrm{~h}$ at $37^{\circ} \mathrm{C}$. The solution absorbance was measured at $450 \mathrm{~nm}$ using the MRX II absorbance reader (Dynex Technologies, Chantilly, VA, USA). Three independent experiments were performed and data are presented as mean \pm standard deviation (SD).

Cell apoptosis assay. ACC-LC-319/bone2 cells transfected with si-MALAT1 were harvested $48 \mathrm{~h}$ after transfection. The cells were resuspended, fixed, resuspended in staining solution and were finally cultured in 6-well plates at a density of $1 \times 10^{5}$ cells/well. The cells were double stained with Annexin V-FITC and propidium iodide (PI) according to the manufacturer's recommendations, and the cells were analyzed with flow cytometry (KeyGen Biotech, Co., Ltd.) equipped with CellQuest software (BD Biosciences). Cells were characterized as viable, dead, early apoptotic and apoptotic cells, and then the relative ratio of early apoptotic cells was compared with the control transfectant from each experiment.

Cell migration and invasion assays. To determine cell migration, similar sized wounds were introduced to monolayer cells using a sterile white pipette tip. Wounded monolayer cells were washed 3 times by phosphate-buffered saline (PBS) to remove cell debris and were then cultured. The speed of wound closure was monitored and photographed at $48 \mathrm{~h}$. To determine cell invasion ability, the ACC-LC-319/bone 2 cells transfected with either si-MALAT1 or si-Con were seeded into 24-well plates with a Matrigel-coated membrane with $8-\mathrm{mm}$ 

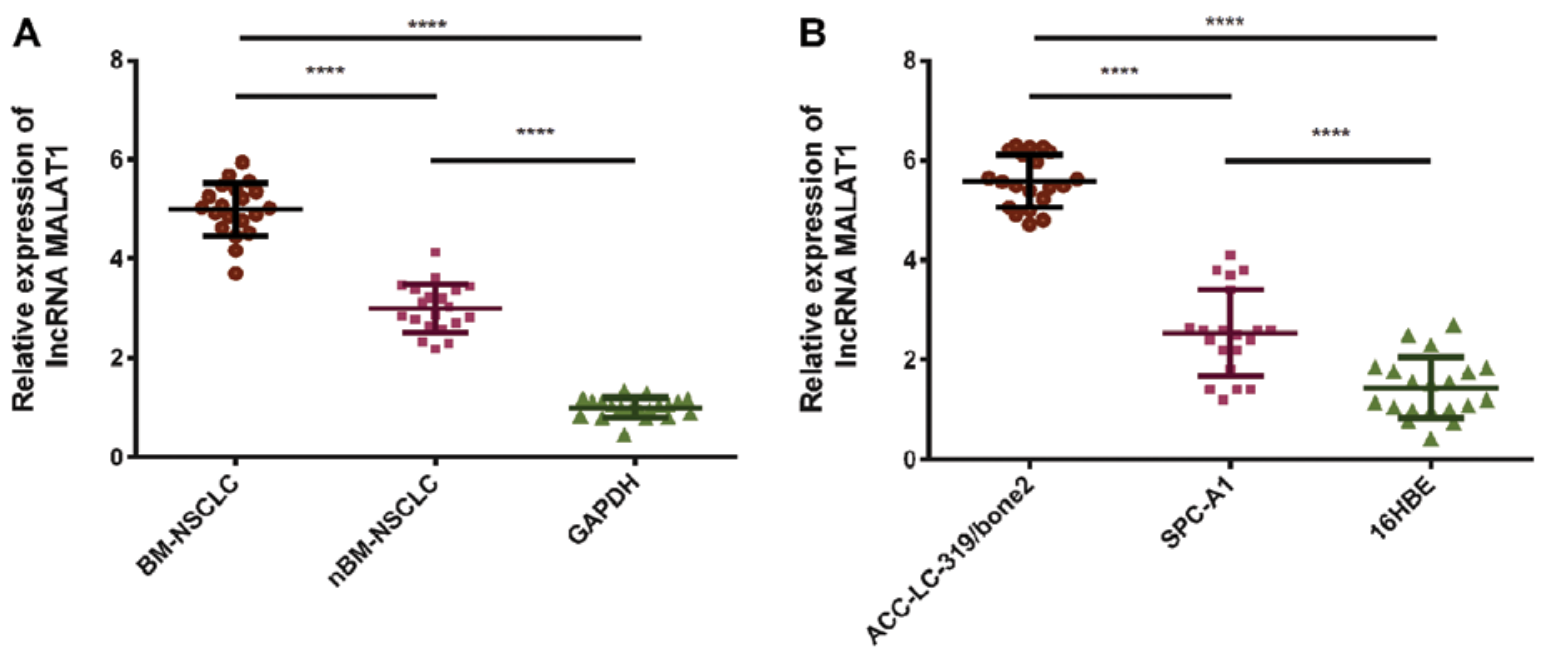

Figure 1. Expression of IncRNA MALAT1 in NSCLC tissues and cell lines. (A) The expression level of lncRNA MALAT1 was markedly higher in the lung tumor tissues with bone metastasis compared with the level in lung tumor tissues without bone metastasis (nBM-NSCLC) (P<0.0001). (B) Human lung adenocarcinoma cell lines ACC-LC-319/bone2 $(\mathrm{P}<0.0001)$ and SPC-A1 $(\mathrm{P}<0.0001)$ were also found to exhibit significantly higher expression of MALAT1 than the normal cell line 16HBE. The expression of MALAT1 in ACC-LC-319/bone2 cells was also significantly higher than that in the cell line SPC-A1 (P<0.0001). MALAT1, metastasis-associated lung adencarcinoma transcript 1; NSCLC, non-small cell lung cancer.

pore size (Costar) chamber inserts. Cells were suspended in $0.2 \mathrm{ml}$ of DMEM without FBS when they were seeded into the upper chamber. In the lower chamber, $0.6 \mathrm{ml}$ of DMEM supplemented with $10 \%$ FBS was added. After incubation for $48 \mathrm{~h}$ at $37^{\circ} \mathrm{C}$ in $5 \% \mathrm{CO}_{2}$, the non-invaded cells on the upper membrane surface were removed with a cotton tip, and the cells that passed through the filter were fixed and stained using $0.1 \%$ crystal violet for $10 \mathrm{~min}$ and placed on a glass slide. The numbers of invaded cells were counted in 3 randomly selected high-power fields under a microscope (Olympus).

Tumor formation assay in a nude mouse model. Female athymic BALB/c nude mice (4-weeks old) were maintained under pathogen-free conditions and maintained according to the protocols approved by the Shanghai Medical Experimental Animal Care Commission. ACC-LC-319/bone2 cells transfected with either si-MALAT1 or si-Con were injected into a single side of the posterior flank of each mouse. Mice were euthanized and the subcutaneous growth of each tumor was examined 18 days after injection. Tumor volume (V) was calculated using the equation: $\mathrm{V}=0.5 \times \mathrm{D} \times \mathrm{d}^{2}(\mathrm{D}$, longitudinal diameter; $d$, latitudinal diameter).

Statistical analysis. Statistical Package for Social Sciences software (SPSS, Inc., Chicago, IL, USA), version 16.0 for Windows was used for statistical analysis. The data are presented as the mean $\pm \mathrm{SD}$, and comparison between groups was assessed by the Student's t-test. Categorical data were analyzed using the two-sided Chi-square test. $\mathrm{P}<0.05$ was considered to indicate a statistically significant difference.

\section{Results}

MALAT1 expression in NSCLC tissues and cell lines. qRT-PCR was used to detect MALAT1 expression levels in cell lines and clinical samples, which were normalized to GAPDH. To investigate the potential role of MALAT1 in the bone metastasis of NSCLC, the expression of lncRNAMALAT1 was assessed in 40 tissue samples from NSCLC patients with (BM-NSCLC, $n=20$ ) or without (nBM-NSCLC, $\mathrm{n}=20$ ) bone metastasis. The relative expression level of lncRNA-MALAT1 was significantly higher in the lung tumor tissues with bone metastasis compared with the level in the tumor tissues without bone metastasis $(\mathrm{P}<0.0001$, Fig. 1A). At the same time, the two human lung adenocarcinoma cell lines ACC-LC-319/bone2 ( $\mathrm{P}<0.0001$, Fig. 1B) and SPC-A1 $(\mathrm{P}<0.0001$, Fig. 1B) were also found to exhibit significantly higher expression of MALAT1 than the level in the normal cell line 16HBE. The expression of MALAT1 in the human lung adenocarcinoma cell line ACC-LC-319/bone2 with high bone metastatic ability was also significantly higher than the expression in the normal human lung adenocarcinoma cell line SPC-A1 $(\mathrm{P}<0.0001$, Fig. 1B).

MALAT1 expression and the proliferation ability of NSCLC. Human lung adenocarcinoma cell line ACC-LC-319/bone2 with high bone metastatic ability was chosen for the proliferation ability assessment. IncRNA-MALAT1 was downregulated with siRNA as previously described (Fig. 2A). Fig. 2B shows that the proliferation abilities of the ACC-LC-319/bone 2 cells decreased significantly after incubation with si-MALAT1. Additionally, the colony formation assay also showed that silencing of MALAT1 significantly decreased the number of colonies formed by the ACC-LC-319/bone2 cells (Fig. 2C and D) compared with the si-Con group. These data suggest that MALAT1 knockdown had the ability to inhibit ACC-LC-319/bone2 cell proliferation.

MALAT1 expression and the migratory and invasive abilities of NSCLC cells. Cell invasion is a significant aspect of cancer progression, and involves the migration of tumor cells into contiguous and distant tissues. The present study performed Transwell and wound-healing assays to determine the effect of MALAT1 knockdown on NSCLC cell invasion 

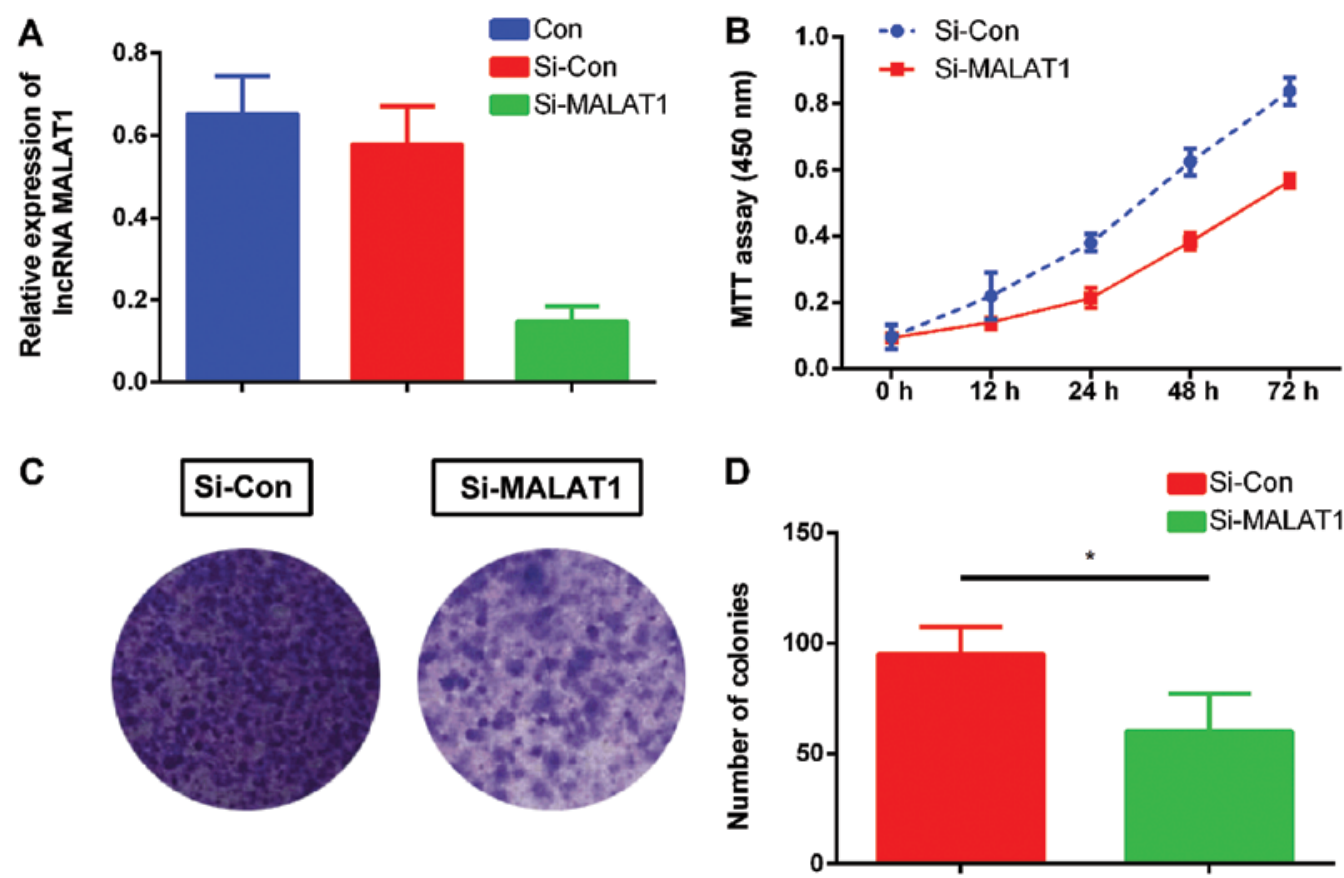

Figure 2. MALAT1 expression and the proliferation ability of NSCLC cells. (A) lncRNA MALAT1 was downregulated with si-MALAT1. (B) The proliferation ability of the ACC-LC-319/bone2 cells was significantly decreased after incubation with si-MALAT1. (C and D) The colony formation assay showed that silencing of MALAT1 significantly decreased the number of colonies formed by the ACC-LC-319/bone2 cells compared with the si-Con group. MALAT1, metastasis-associated lung adencarcinoma transcript 1; NSCLC, non-small cell lung cancer.

A

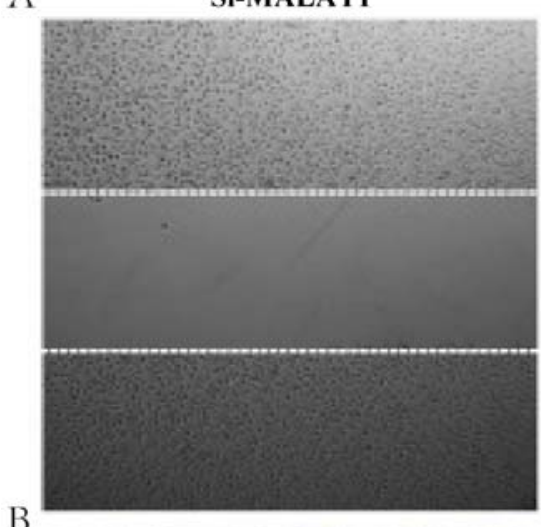

B

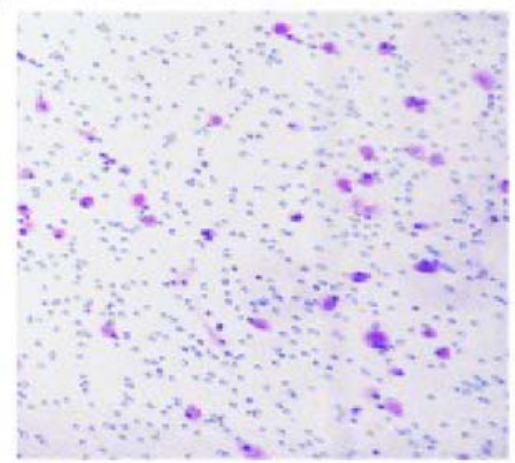

Si-Con
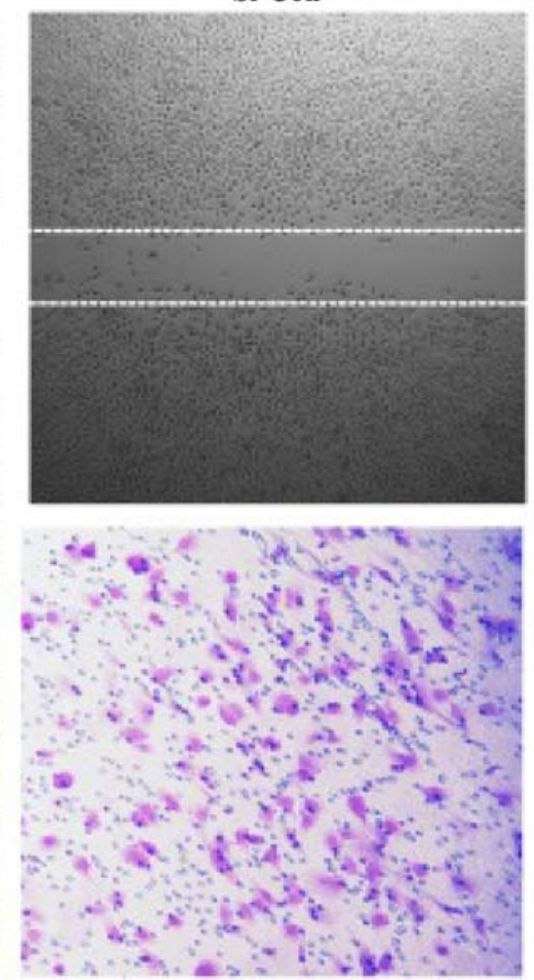

Figure 3. MALAT1 expression and the migratory and invasive abilities of NSCLC cells. (A) The silencing of MALAT1 expression in ACC-LC-319/bone2 cells significantly decreased the migratory ability compared with the normal ACC-LC-319/bone2 cells. (B) The Transwell assay demonstrated that the invasive potential was significantly reduced in the Si-MALAT1 group compared to the Si-Con group. MALAT1, metastasis-associated lung adencarcinoma transcript 1; NSCLC, non-small cell lung cancer.

and metastasis. As shown in Fig. 3, the silencing of MALAT1 expression in ACC-LC-319/bone2 cells decreased the migra- tory ability significantly compared with that in the normal ACC-LC-319/bone2 cells (Fig. 3A). Furthermore, a Transwell 

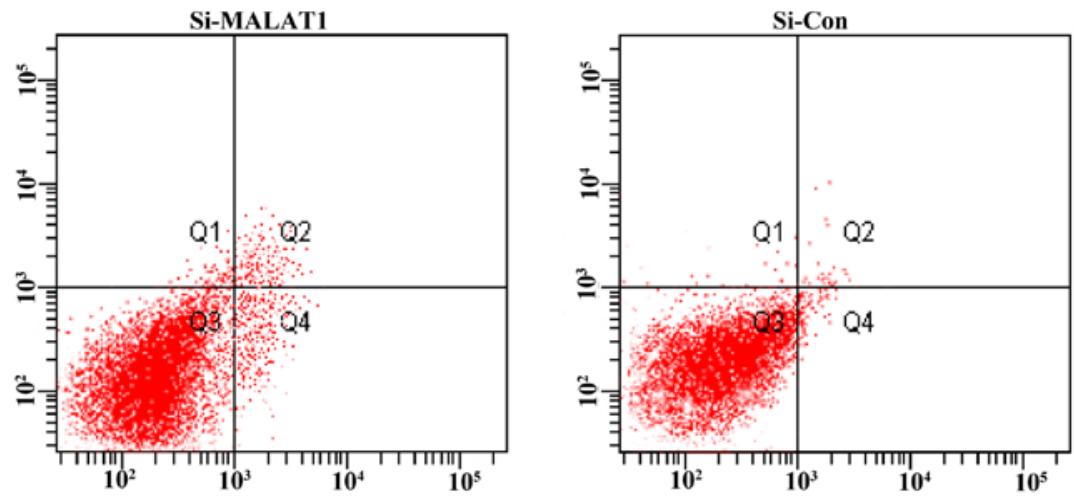

Figure 4. MALAT1 expression and apoptosis of NSCLC. The percentage of apoptotic cells was significantly increased in the ACC-LC-319/bone2 cells transfected with Si-MALAT1 in comparison with the negative controls. MALAT1, metastasis-associated lung adencarcinoma transcript 1; NSCLC, non-small cell lung cancer.

A

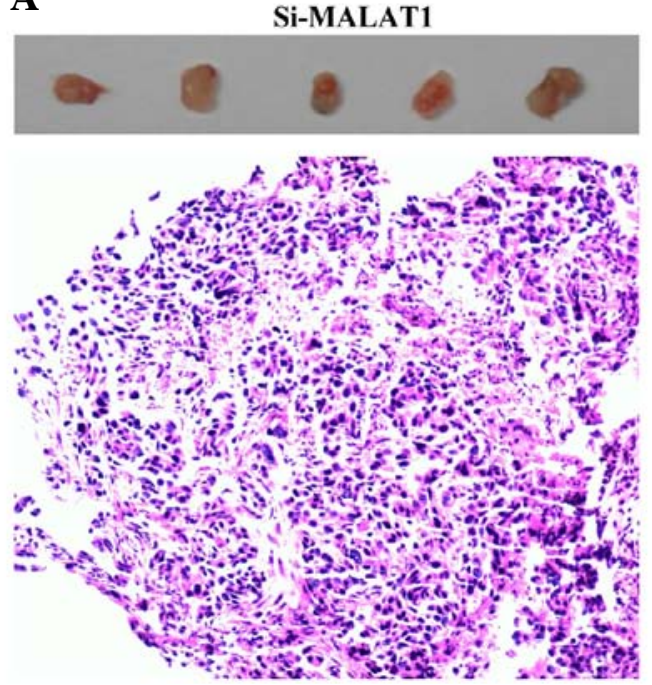

B
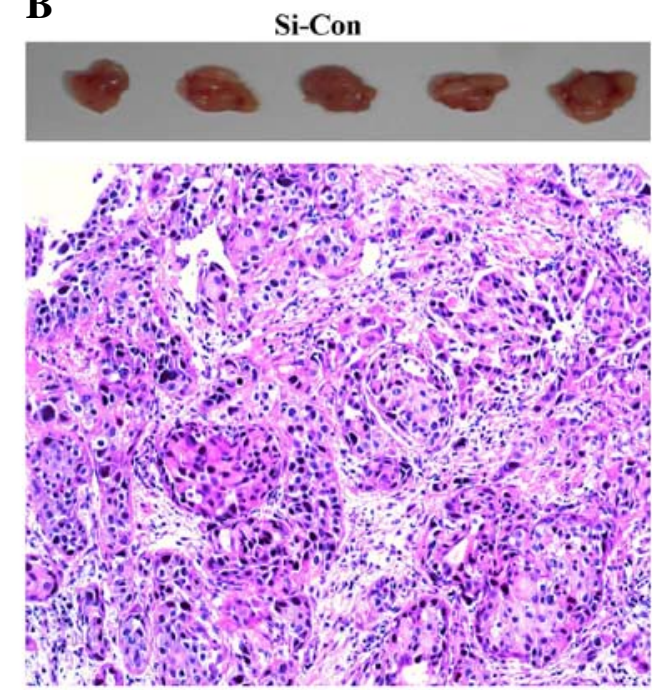

Figure 5. MALAT1 expression and NSCLC cell tumorigenesis in vivo. (A) Tumors formed in the Si-MALAT1 group. (B) Tumors formed in the Si-Con group. MALAT1, metastasis-associated lung adencarcinoma transcript 1; NSCLC, non-small cell lung cancer.

assay was performed to determine the ability of cells to invade a matrix barrier and the representative micrographs are presented in Fig. 3B. The invasive cell count demonstrated that invasive potential was significantly reduced in the Si-MALAT1 group relative to the si-Con group.

MALAT1 expression and apoptosis of NSCLC. As shown in Fig. 4, after treatment with the siRNA for $48 \mathrm{~h}$, the percentage of apoptotic cells was significantly increased in the ACC-LC-319/bone2 cells in comparison with the negative controls.

Downregulation of MALAT1 inhibits NSCLC cell tumorigenesis in vivo. To explore whether the level of MALAT1 expression affects tumorigenesis, ACC-LC-319/bone 2 cells stably transfected with si-MALAT1 or the empty vector were inoculated into nude mice. Eighteen days after the injection, the tumors formed in the si-MALAT1 group were substantially smaller than those that formed in the control group (Fig. 5).

\section{Discussion}

In the present study, we investigated the clinical significance of MALAT1 in NSCLC patients with bone metastasis for the first time. Using qRT-PCR, our results indicated that lncRNA MALAT1 was upregulated in NSCLC patients with bone metastasis and lung cancer cells with high bone metastatic ability when compared with the normal NSCLC tumor tissues, normal human lung adenocarcinoma cell line SPC-A1 and normal human bronchial epithelial cell line 16HBE. The present study also found that expression of IncRNA-MALAT1 was involved in increasing the cellular proliferation ability and inhibiting apoptosis of the NSCLC cells. Moreover, lncRNA-MALAT1 promoted the migration, invasion and tumorigenesis in vivo of NSCLC cells which suggest its important role in the bone metastasis of NSCLC.

Long non-coding RNAs, which are $>200$ nt in length, are unable to be translated into proteins. Recently, more and more studies have shown that dysregulation of lncRNAs is associated with the progression of cancer, such as HOX antisense 
intergenic RNA (HOTAIR), cancer-upregulated drug resistant (CUDR), prostate-specific transcript 1 (PCGEM1), and can be used as biomarkers and prognosis factors (11). There is also increasing evidence suggesting that these lncRNAs are involved in the biological behavior of cancer cells, including proliferative capability and replicative immortality, activation of invasion and metastasis, and induction of angiogenesis and resistance of cell death $(34,35)$.

MALAT1, also known as nuclear-enriched transcript 2, was originally identified in 2003 via subtractive hybridization as a prognostic marker for lung cancer metastasis. Currently, more and more evidence has linked MALAT1 to several other human tumor entities. Gutschner et al showed that MALAT1deficient lung cancer cells demonstrated impaired migratory ability and formed fewer tumors (36). Ji et al reported the increased proliferation and migration effect of MALAT1 in LoVo and HCT116 cells (27). A recent loss-of-function study also unraveled the regulatory effect of MALAT1 in gene expression governing hallmarks of lung cancer metastasis (36). Ren $e t$ al reported the increased expression of MALAT-1 in prostate cancer which was correlated with Gleason score, prostate-specific antigen, tumor stage and castration-resistant prostate cancer. Moreover, downregulation of MALAT-1 significantly inhibited the cell growth, invasion and migration of prostate cancer cells (37).

Alhough the effect of IncRNA MALAT1 in tumor growth and invasion is well known, the effective mechanism still needs further investigation. MALAT1 is specifically retained in nuclear speckles, and MALAT1 functions as storage for small RNAs which is broadly expressed in human tissues (38-41). Another study reported that MALAT1 regulates the alternative splicing of pre-mRNAs by modulating the levels of active serine/arginine splicing factors. Recent studies have also reported that the effects of IncRNA MALAT1 are associated with tumor-suppressor gene SFPQ and proto-oncogene PTBP2. MALAT1 was found to inhibit the combination of SFPQ protein with proto-oncogene GAGE6 transcriptional regulatory regions, thus releasing PTBP2 from the SFPQ/PTBP2 complex and promoting cell proliferation and migration (42-44). Ying et al demonstrated that MALAT1 promoted bladder cancer cell migration by activating the Wnt pathway (45), and Wu et al suggested that MALAT1 promotes the proliferation and metastasis of gallbladder cancer cells by activating the ERK/MAPK pathway (46). Another study indicated that MALAT1 suppresses tumor growth and metastasis via the PI3K/AKT signaling pathway (47). In addition, mutations enriched in the 3'-end of MALAT1 in the MALAT1 gene were recently discovered in breast cancer and CRC $(40,48)$, and these mutations were able to promote invasive behavior (40). Guo et al showed that the effect of MALAT1 was achieved through the regulation of gene expression, such as caspase- 3 and $-8, \mathrm{Bcl}-2$, Bax and Bcl-xL (31). In contrast, Tripathi et al reported a critical involvement of MALAT1 in genome stability and cell cycle checkpoint [MALAT1 depletion results in an increased level of $\gamma \mathrm{H} 2 \mathrm{AX}$ (a DNA damage indicator) and accumulation of the G2/M population]. Previous studies have also found that the expression level of MALAT1 is controlled by methylation of histone $\mathrm{H} 3$ (49), transcriptional factors $(50)$ and microRNAs $(51,52)$; however, evidence to explain its overexpression in diverse tumor tissues is lacking.
In conclusion, the present study demonstrated that lncRNA MALAT1 was upregulated in NSCLC tissues with bone metastasis and in lung cancer cell lines with high bone metastatic ability. The present study also found that expression of IncRNA MALAT1 was involved in increasing the cellular proliferation ability and inhibiting apoptosis of the NSCLC cells. In adddition, IncRNA MALAT1 promoted the migration, invasion and tumorigenesis in vivo of NSCLC cells which suggest the important role of MALAT1 in the bone metastasis of NSCLC.

\section{References}

1. Siegel R, Naishadham D and Jemal A: Cancer statistics, 2013. CA Cancer J Clin 63: 11-30, 2013.

2. Jemal A, Siegel R, Xu J and Ward E: Cancer statistics, 2010. CA Cancer J Clin 60: 277-300, 2010.

3. Gridelli C, Rossi A, Maione P, Ferrara ML, Castaldo V and Sacco PC: Vaccines for the treatment of non-small cell lung cancer: A renewed anticancer strategy. Oncologist 14: 909-920, 2009.

4. Verdecchia A, Francisci S, Brenner H, Gatta G, Micheli A, Mangone L, Kunkler I; EUROCARE-4 Working Group: Recent cancer survival in Europe: A 2000-02 period analysis of EUROCARE-4 data. Lancet Oncol 8: 784-796, 2007.

5. Pastorino U: Lung cancer screening. Br J Cancer 102: 1681-1686, 2010.

6. Ponting CP, Oliver PL and Reik W: Evolution and functions of long noncoding RNAs. Cell 136: 629-641, 2009.

7. Wilusz JE, Sunwoo H and Spector DL: Long noncoding RNAs: Functional surprises from the RNA world. Genes Dev 23: 1494-1504, 2009.

8. Mercer TR, Dinger ME and Mattick JS: Long non-coding RNAs: Insights into functions. Nat Rev Genet 10: 155-159, 2009.

9. Gupta RA, Shah N, Wang KC, Kim J, Horlings HM, Wong DJ, Tsai MC, Hung T, Argani P, Rinn JL, et al: Long non-coding RNA HOTAIR reprograms chromatin state to promote cancer metastasis. Nature 464: 1071-1076, 2010.

10. Loewer S, Cabili MN, Guttman M, Loh YH, Thomas K, Park IH, Garber M, Curran M, Onder T, Agarwal S, et al: Large intergenic non-coding RNA-RoR modulates reprogramming of human induced pluripotent stem cells. Nat Genet 42: 1113-1117, 2010.

11. Esteller M: Non-coding RNAs in human disease. Nat Rev Genet 12: 861-874, 2011.

12. Gibb EA, Brown CJ and Lam WL: The functional role of long non-coding RNA in human carcinomas. Mol Cancer 10: 38, 2011.

13. Wang J, Liu X, Wu H, Ni P, Gu Z, Qiao Y, Chen N, Sun F and Fan Q: CREB up-regulates long non-coding RNA, HULC expression through interaction with microRNA-372 in liver cancer. Nucleic Acids Res 38: 5366-5383, 2010.

14. Khaitan D, Dinger ME, Mazar J, Crawford J, Smith MA, Mattick JS and Perera RJ: The melanoma-upregulated long noncoding RNA SPRY4-IT1 modulates apoptosis and invasion. Cancer Res 71: 3852-3862, 2011.

15. Yang F, Zhang L, Huo XS, Yuan JH, Xu D, Yuan SX, Zhu N, Zhou WP, Yang GS, Wang YZ, et al: Long noncoding RNA high expression in hepatocellular carcinoma facilitates tumor growth through enhancer of zeste homolog 2 in humans. Hepatology 54: 1679-1689, 2011.

16. Cui Z, Ren S, Lu J, Wang F, Xu W, Sun Y, Wei M, Chen J, Gao X, $\mathrm{Xu} \mathrm{C}$, et al: The prostate cancer-up-regulated long noncoding RNA PlncRNA-1 modulates apoptosis and proliferation through reciprocal regulation of androgen receptor. Urol Oncol 31: 1117-1123, 2013.

17. Wang Y, Chen W, Yang C, Wu W, Wu S, Qin X and Li X: Long non-coding RNA UCAla(CUDR) promotes proliferation and tumorigenesis of bladder cancer. Int J Oncol 41: 276-284, 2012.

18. Jin G, Sun J, Isaacs SD, Wiley KE, Kim ST, Chu LW, Zhang Z, Zhao $\mathrm{H}$, Zheng SL, Isaacs WB, et al: Human polymorphisms at long non-coding RNAs (lncRNAs) and association with prostate cancer risk. Carcinogenesis 32: 1655-1659, 2011.

19. Kotake Y, Nakagawa T, Kitagawa K, Suzuki S, Liu N, Kitagawa M and Xiong Y: Long non-coding RNA ANRIL is required for the PRC2 recruitment to and silencing of $\mathrm{p} 15^{\mathrm{INK} 4 \mathrm{~B}}$ tumor suppressor gene. Oncogene 30: 1956-1962, 2011. 
20. Zhou Y, Zhang X and Klibanski A: MEG3 noncoding RNA: A tumor suppressor. J Mol Endocrinol 48: R45-R53, 2012.

21. Geng YJ, Xie SL, Li Q, Ma J and Wang GY: Large intervening non-coding RNA HOTAIR is associated with hepatocellular carcinoma progression. J Int Med Res 39: 2119-2128, 2011.

22. Kim K, Jutooru I, Chadalapaka G, Johnson G, Frank J, Burghardt R, Kim S and Safe S: HOTAIR is a negative prognostic factor and exhibits pro-oncogenic activity in pancreatic cancer. Oncogene 32: 1616-1625, 2013.

23. Tu ZQ, Li RJ, Mei JZ and Li XH: Down-regulation of long non-coding RNA GAS5 is associated with the prognosis of hepatocellular carcinoma. Int J Clin Exp Pathol 7: 4303-4309, 2014.

24. Yan TH, Lu SW, Huang YQ, Que GB, Chen JH, Chen YP, Zhang HB, Liang XL and Jiang JH: Upregulation of the long noncoding RNA HOTAIR predicts recurrence in stage $\mathrm{Ta} / \mathrm{T} 1$ bladder cancer. Tumour Biol 35: 10249-10257, 2014.

25. Liu XH, Lu KH, Wang KM, Sun M, Zhang EB, Yang JS, Yin DD, Liu ZL, Zhou J, Liu ZJ, et al: MicroRNA-196a promotes non-small cell lung cancer cell proliferation and invasion through targeting HOXA5. BMC Cancer 12: 348, 2012.

26. Gutschner T, Hämmerle M, Eissmann M, Hsu J, Kim Y, Hung G, Revenko A, Arun G, Stentrup M, Gross M, et al: The noncoding RNA MALAT1 is a critical regulator of the metastasis phenotype of lung cancer cells. Cancer Res 73: 1180-1189, 2013.

27. Ji P, Diederichs S, Wang W, Böing S, Metzger R, Schneider PM, Tidow N, Brandt B, Buerger H, Bulk E, et al: MALAT-1, a novel noncoding RNA, and thymosin beta4 predict metastasis and survival in early-stage non-small cell lung cancer. Oncogene 22: 8031-8041, 2003.

28. Hutchinson JN, Ensminger AW, Clemson CM, Lynch CR, Lawrence JB and Chess A: A screen for nuclear transcripts identifies two linked noncoding RNAs associated with SC35 splicing domains. BMC Genomics 8: 39, 2007.

29. Tseng JJ, Hsieh YT, Hsu SL and Chou MM: Metastasis associated lung adenocarcinoma transcript 1 is up-regulated in placenta previa increta/percreta and strongly associated with trophoblastlike cell invasion in vitro. Mol Hum Reprod 15: 725-731, 2009.

30. Lin R, Maeda S, Liu C, Karin M and Edgington TS: A large noncoding RNA is a marker for murine hepatocellular carcinomas and a spectrum of human carcinomas. Oncogene 26 : 851-858, 2007.

31. Guo F, Li Y, Liu Y, Wang J, Li Y and Li G: Inhibition of metastasis-associated lung adenocarcinoma transcript 1 in CaSki human cervical cancer cells suppresses cell proliferation and invasion. Acta Biochim Biophys Sin 42: 224-229, 2010.

32. Zheng HT, Shi DB, Wang YW, Li XX, Xu Y, Tripathi P, Gu WL, Cai GX and Cai SJ: High expression of IncRNA MALAT1 suggests a biomarker of poor prognosis in colorectal cancer. Int J Clin Exp Pathol 7: 3174-3181, 2014.

33. Schmidt LH, Spieker T, Koschmieder S, Schäffers S, Humberg J, Jungen D, Bulk E, Hascher A, Wittmer D and Marra A: The long noncoding MALAT-1 RNA indicates a poor prognosis in non-small cell lung cancer and induces migration and tumor growth. J Thorac Oncol 6: 1984-1992, 2011.

34. Yuan SX, Yang F, Yang Y, Tao QF, Zhang J, Huang G, Yang Y, Wang RY, Yang S, Huo XS, et al: Long noncoding RNA associated with microvascular invasion in hepatocellular carcinoma promotes angiogenesis and serves as a predictor for hepatocellular carcinoma patients' poor recurrence-free survival after hepatectomy. Hepatology 56: 2231-2241, 2012.

35. Gutschner T and Diederichs S: The hallmarks of cancer: A long non-coding RNA point of view. RNA Biol 9: 703-719, 2012.

36. Gutschner T, Hämmerle $\mathrm{M}$ and Diederichs S: MALAT1 - a paradigm for long noncoding RNA function in cancer. $\mathrm{J}$ Mol Med Berl 91: 791-801, 2013.

37. Ren S, Liu Y, Xu W, Sun Y, Lu J, Wang F, Wei M, Shen J, Hou J, Gao X, et al: Long noncoding RNA MALAT-1 is a new potential therapeutic target for castration resistant prostate cancer. J Urol 190: 2278-2287, 2013.
38. Wilusz JE, Freier SM and Spector DL: 3' end processing of a long nuclear-retained noncoding RNA yields a tRNA-like cytoplasmic RNA. Cell 135: 919-932, 2008

39. Tripathi V, Ellis JD, Shen Z, Song DY, Pan Q, Watt AT, Freier SM, Bennett CF, Sharma A, Bubulya PA, et al: The nuclear-retained noncoding RNA MALAT1 regulates alternative splicing by modulating SR splicing factor phosphorylation. Mol Cell 39: 925-938, 2010

40. Xu C, Yang M, Tian J, Wang X and Li Z: MALAT-1: A long non-coding RNA and its important 3 ' end functional motif in colorectal cancer metastasis. Int J Oncol 39: 169-175, 2011.

41. Birney E, Stamatoyannopoulos JA, Dutta A, Guigó R, Gingeras TR, Margulies EH, Weng Z, Snyder M, Dermitzakis ET, Thurman RE, et al; Children's Hospital Oakland Research Institute: Identification and analysis of functional elements in $1 \%$ of the human genome by the ENCODE pilot project. Nature 447: 799-816, 2007.

42. Li L, Feng T, Lian Y, Zhang G, Garen A and Song X: Role of human noncoding RNAs in the control of tumorigenesis. Proc Natl Acad Sci USA 106: 12956-12961, 2009.

43. Ji Q, Zhang L, Liu X, Zhou L, Wang W, Han Z, Sui H, Tang Y, Wang Y, Liu N, et al: Long non-coding RNA MALAT1 promotes tumour growth and metastasis in colorectal cancer through binding to SFPQ and releasing oncogene PTBP2 from SFPQ/PTBP2 complex. Br J Cancer 111: 736-748, 2014.

44. Meissner M, Dechat T, Gerner C, Grimm R, Foisner R and Sauermann G: Differential nuclear localization and nuclear matrix association of the splicing factors PSF and PTB. J Cell Biochem 76: 559-566, 2000.

45. Ying L, Chen Q, Wang Y, Zhou Z, Huang Y and Qiu F: Upregulated MALAT-1 contributes to bladder cancer cell migration by inducing epithelial-to-mesenchymal transition. Mol Biosyst 8: 2289-2294, 2012.

46. Wu XS, Wang XA, Wu WG, Hu YP, Li ML, Ding Q, Weng H, Shu YJ, Liu TY, Jiang L, et al: MALAT1 promotes the proliferation and metastasis of gallbladder cancer cells by activating the ERK/MAPK pathway. Cancer Biol Ther 15: 806-814, 2014.

47. Dong Y, Liang G, Yuan B, Yang C, Gao R and Zhou X: MALAT1 promotes the proliferation and metastasis of osteosarcoma cells by activating the PI3K/Akt pathway. Tumour Biol 36: 1477-1486, 2015.

48. Ellis MJ, Ding L, Shen D, Luo J, Suman VJ, Wallis JW, Van Tine BA, Hoog J, Goiffon RJ, Goldstein TC, et al: Whole-genome analysis informs breast cancer response to aromatase inhibition. Nature 486: 353-360, 2012

49. Tee AE, Ling D, Nelson C, Atmadibrata B, Dinger ME, Xu N, Mizukami T, Liu PY, Liu B, Cheung B, et al: The histone demethylase JMJD1A induces cell migration and invasion by up-regulating the expression of the long noncoding RNA MALAT1. Oncotarget 5: 1793-1804, 2014.

50. Fan Y, Shen B, Tan M, Mu X, Qin Y, Zhang F and Liu Y: TGF- $\beta$-induced upregulation of malat 1 promotes bladder cancer metastasis by associating with suz12. Clin Cancer Res 20: $1531-1541,2014$

51. Han Y, Liu Y, Zhang H, Wang T, Diao R, Jiang Z, Gui Y and Cai Z: Hsa-miR-125b suppresses bladder cancer development by down-regulating oncogene SIRT7 and oncogenic long noncoding RNA MALAT1. FEBS Lett 587: 3875-3882, 2013.

52. Leucci E, Patella F, Waage J, Holmstrøm K, Lindow M, Porse B, Kauppinen S and Lund AH: microRNA-9 targets the long non-coding RNA MALAT1 for degradation in the nucleus. Sci Rep 3: 2535, 2013. 